\title{
FOTOGRAFIAS, ARTE E MUSEUS: DA COLISÃO À EXPANSÃO
}

Resumo: Este artigo aborda a associação existente entre fotografia, arte contemporânea e museus, procurando investigar os modos como ela foi sendo desafiada pela revolução digital. A partir da obra de Joachim Schmid, este trabalho examina as estratégias museológicas que o artista desenvolveu, e subverteu, na sua prática, para questionar e reconfigurar os enquadramentos institucionais da arte e dos museus. Questões relacionadas com a reciclagem e a (i)materialidade dos objectos fotográficos são aqui particularmente aprofundadas para compreender as novas formas de apropriação artística e de legitimação cultural que caracterizam o actual contexto tecnológico da fotografia.

Palavras-chave: Fotografia - Apropriação - Revolução digital - Museus - Crítica institucional - Joachim Schmid.

Susana S. Martins Instituto de História de Arte Universidade Nova de Lisboa susanamsmartins@gmail.com

\section{PHOTOGRAPHS, ART AND MUSEUMS: FROM COLLISION TO EXPANSION}

\begin{abstract}
This article discusses the existing association between photography, contemporary art and museums, investigating also the ways in which it has been challenged by the digital revolution. Drawing on the work of Joachim Schmid, this work examines the museological strategies the artist developed and subverted in his practice, in order to challenge the institutional frameworks of art and museums. Issues of materiality and recycling of photographic objects are particularly analyzed here, aiming to understand the new forms of artistic appropriation and cultural legitimation that characterize the current technological context of photography.
\end{abstract}

Keywords: Photography - Appropriation - Digital revolution - Museums - Institutional critique Joachim Schmid. 


\section{A INQUIETAÇÃO DA ARTE PERANTE O MUSEU}

$\mathrm{Na}$ presente era dita pós-digital, marcada por novas plataformas de circulação da imagem e por uma progressiva diluição de fronteiras entre o público e o privado, as práticas da fotografia afirmam-se como sendo cada vez mais numerosas, dinâmicas e 'imateriais'. Paralelamente, porém, assiste-se a uma peculiar valorização daquilo que são os 'objectos' fotográficos. Perante a ameaça do seu desaparecimento, tão inevitável como premente, a recuperação da tradicional materialidade da fotografia realiza-se em diversas frentes, enquanto impulso nostálgico, arqueológico, criativo e institucional. No campo da fotografia artística contemporânea, este reencontro com a materialidade da fotografia tem sido especialmente forte: o 'passado', a 'história', o 'museu' ou o 'arquivo', são intensamente convocados, enquanto categorias maleáveis e deliberadamente instáveis, para pensar e questionar o presente. Deste modo, os artistas têm procurado reinventar os modos, usos e circuitos da fotografia, ao mesmo tempo que pretendem questionar e dialogar com novas formas de legitimação cultural e institucional. O presente artigo investiga algumas das transmutações e continuidades da fotografia a partir do trabalho artístico de Joachim Schmid e da sua permanente colisão com os conceitos e dispositivos museológicos.

Sabemos que a tensão que caracteriza a relação histórica e cultural entre artistas, museus e exposições não é propriamente nova. A teia de confrontos e dependências que estruturam a interligação entre estes três elementos - artistas, museus e exposições - é complexa e bem documentada em casos paradigmáticos. Um olhar breve sobre o passado recente permite verificar como, desde o Salon des Refusés de 1863 aos ready-mades das primeiras vanguardas do século XX, desde os gestos performativos dos anos de 1960 que procuravam esbater, fora do museu, as fronteiras entre a arte e a vida, às práticas pósmodernas que integraram as noções de cópia, simulacro e apropriação como categorias artísticas dominantes, têm sido muitos e variados os momentos que atestam a dificuldade desta ligação.

O nascimento dos museus, enquanto instituições cruciais da modernidade ocidental no final do século XVIII, foi acompanhado pela progressiva emergência de novos locais para a exposição pública da arte. Este aspecto revelou-se decisivo não apenas no entendimento do papel do artista nas sociedades modernas e contemporâneas mas também na definição dos mercados e da crítica de arte, tal como hoje os conhecemos. Mas apesar da estreita dependência entre artistas e museus, esta interacção tem sido, em muitos aspectos, ambivalente e contraditória. 
$\mathrm{Na}$ origem desta relação inquieta está o facto de os museus serem muitas vezes lidos como instituições conservadoras, viradas para o passado, e com inevitáveis conotações de declínio e morte. Theodor Adorno, uma das vozes mais influentes nesta matéria, assinalou que os termos "museu e mausoléu" se encontravam "ligados para além das suas semelhanças fonéticas". No seu entender, os museus "são como sepulcros das obras de arte", uma vez que a sua função se prende com a exposição de objectos que se encontram já em "processo de morte" (ADORNO, 1967, p. 175). Embora o célebre posicionamento de Adorno seja certamente exagerado, as suas palavras ressoam, ainda hoje, com alguma pertinência. Em particular, porque persiste um entendimento dos museus que ainda os entende como locais de reclusão, onde as obras (de arte) são frequentemente retiradas, em profunda descontextualização, dos seus ambientes originais.

Estes aspectos ajudam a explicar, de certo modo, a natureza delicada da relação entre museus e arte contemporânea. Retrospectivamente, verifica-se que esta incompatibilidade histórica entre o que integra um museu e o que define a produção artística contemporânea, é algo que se encontra menos vincada nos dias de hoje, uma vez que muito do diálogo que os artistas actualmente estabelecem com as instituições museológicas procura incorporar, precisamente, esta já mítica oposição. Não apenas porque a crítica institucional configura, desde há muito, um território frutífero no qual os artistas têm vindo a desafiar e a romper criticamente com as funções clássicas do museu (WARD, 1995; McSHINE, 1999; FRASER, 2005), mas também porque os museus - e em particular os museus de arte - são estruturas de legitimação cultural particularmente apreciadas pelos artistas contemporâneos e pelos seus coleccionadores. Uma obra de arte que seja exposta num museu, tornar-se-á num objecto singular, merecedor de considerável apreciação colectiva, e provavelmente conquistará um lugar nas futuras narrativas da história da arte. É este o poder do "efeito-museu" para usar a expressão cunhada por André Malraux que evidencia como a mera exposição de um objecto, num museu, é suficiente para lhe atribuir importância e valor (MALRAUX, 1965, p.14).

Os mercados da arte, os coleccionadores, ou as galerias parecem ser especialmente sensíveis ao valor que os museus são capazes de atribuir a uma obra de arte - seja ele estético, comercial ou cultural. Os museus assumem assim um papel preponderante na difícil tarefa de "coleccionar o novo" . Além disso, o facto de um artista ter a possibilidade de entrar num museu, e ao mesmo tempo poder resistir e rebelar-se contra os seus constrangimentos,

\footnotetext{
${ }^{1}$ Estou aqui a tomar de empréstimo o título do livro de Bruce Altshueler (ALTSHULER, 2007).
} 
constitui um dos mais poderosos e estimulantes legados da duradoura relação que se estabeleceu entre artistas contemporâneos e museus.

Neste cenário onde confluem artistas e museus, há que considerar ainda a importância de um terceiro elemento: a fotografia. O impacto da fotografia nos museus não é inédito; tanto numa perspectiva prática como teórica, este fenómeno tem sido alvo de atenção. Sobretudo André Malraux, no seu texto pioneiro de 1965, Le Musée Imaginaire, foi um dos principais autores a considerar a fotografia responsável por uma série de transformações centrais que ocorreram no âmbito dos museus. Segundo Malraux, a fotografia enquanto medium reprodutível, permitiu colocar em prática uma análise comparativa única que mudou radicalmente o rosto da história da arte e dos seus métodos. No entender do autor, a história de arte tornou-se até certo ponto "na história daquilo que pode ser fotografado"(MALRAUX, 1965, p.76). Além do mais, ao promover a grande acessibilidade visual às obras de arte, a fotografia contribui ainda para derrubar, democraticamente, muitas das barreiras que as paredes dos museus pareciam erguer face aos seus públicos.

Mais tarde, em 1980, Douglas Crimp - outra figura incontornável no debate entre fotografia e museus - sugeria que a fotografia não tornou apenas as obras de arte mais disponíveis para integrar o museu imaginário, e potencialmente infinito, de Malraux. O aspecto mais importante para o autor é que a fotografia chegou igualmente às paredes do museu, uma vez que o seu estatuto artístico foi sendo progressivamente reconhecido (CRIMP, 1980, 1980a). Avaliando o modo como o poder pós-aurático da fotografia se tornou finalmente mais visível na arte pós-moderna, Crimp examina ainda de que forma a fotografia despoletou grande parte das preocupações pós-modernistas, abordando as noções de originalidade, autenticidade e presença - que acabaram, em última análise, por tornar o papel do museu cada vez menos estável.

Este texto propõe, assim, avaliar quão fundamental foi o papel da fotografia na ligação entre artistas e museus, através da perspectiva da arte contemporânea. Para o efeito, analisarse-á a obra do artista alemão Joachim Schmid, dando particular destaque às estratégias e noções museológicas que o artista incorpora nas suas obras, muitas vezes de forma contraditória, mas também aos projectos através dos quais reage e responde directamente ao universo dos museus. Num momento em que a fotografia participa vigorosamente da revolução digital investigar-se-á ainda de que forma o trabalho de Schmid, na sua vertente cada vez mais imaterial, destabiliza as temporalidades e funções clássicas do museu. 


\section{UM ORIGINAL MÉTODO DE FALSIFICAÇÃO}

Em primeiro lugar, importa esclarecer que este texto investiga o papel da fotografia no diálogo entre artistas e museus, através do trabalho de um artista que se distingue precisamente por praticamente não fotografar. Apesar de Joachim Schmid não ser fotógrafo no sentido mais clássico do termo, esta escolha justifica-se porque o seu trabalho é, ainda assim, profundamente fotográfico. No geral, a sua obra suscita questões pertinentes sobre a natureza da fotografia, questionando o modo como os objectos fotográficos, apesar das suas sucessivas transformações históricas e tecnológicas, conseguem persistir, sobreviver e funcionar na cultura contemporânea. Além disso, muitas destas questões giram precisamente em torno de estratégias artísticas que, directa ou indirectamente, envolvem o museu. Neste sentido, o meu objectivo aqui será o de investigar a maneira complementar como Joachim Schmid incorpora várias noções museológicas no seu trabalho: a) não apenas para desafiar e colocar em causa os valores, assunções e hierarquias que os museus frequentemente ajudam a validar; b) mas também para encontrar novas formas de superar a própria relação entre arte contemporânea e museus.

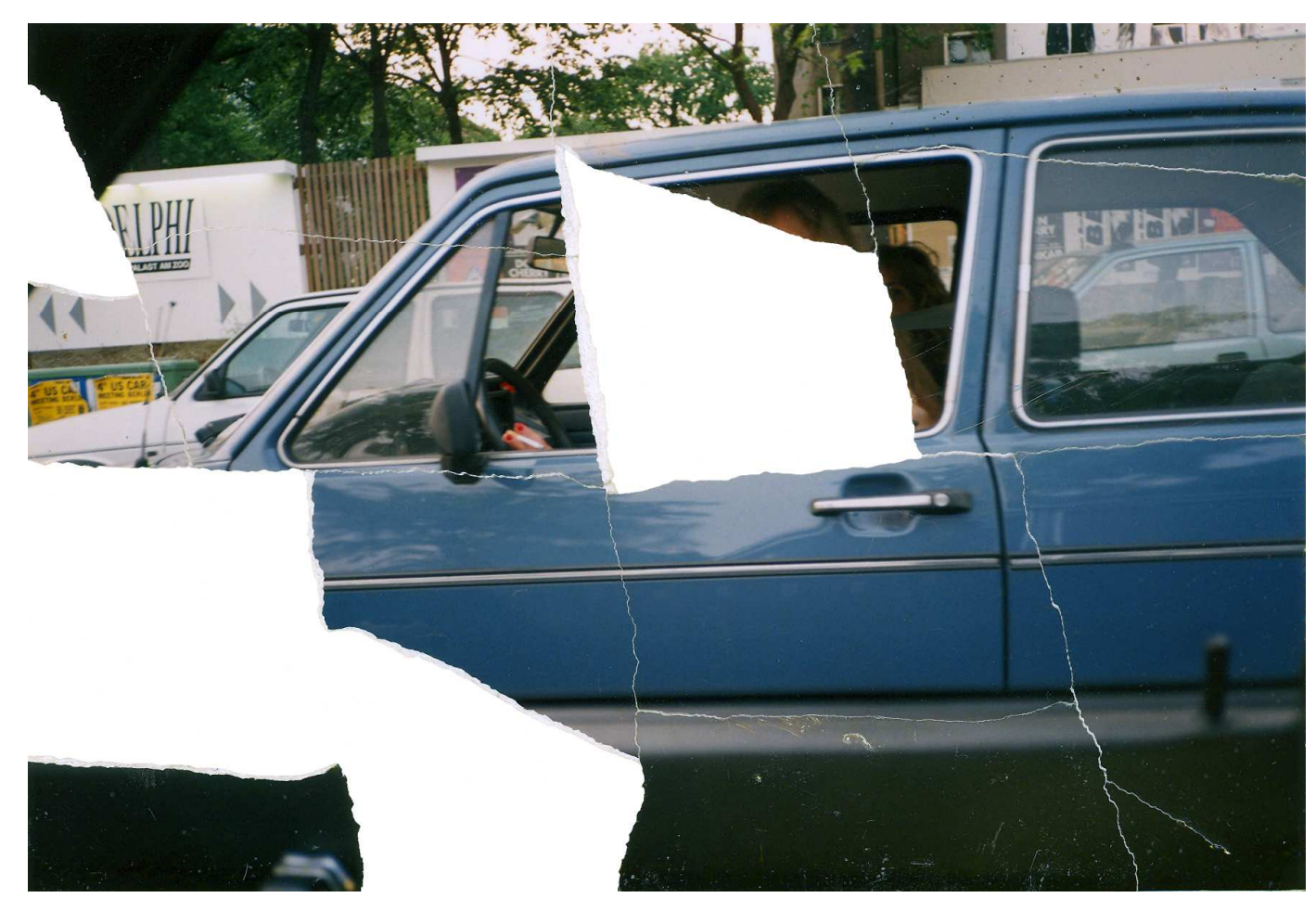

Fig.1.

Joachim Schmid, Bilder von der Straße, 1982-2012. No. 83: Berlin, July 1990. Fonte: http://schmid.wordpress.com/ 
Embora Joachim Schmid não seja exactamente um fotógrafo, desde os anos de 1980 que tem trabalhado de forma consistente com fotografias em segunda mão, geralmente de origem desconhecida. Projectos importantes como Bilder von der Straße (1982-2012), Archiv (1986-1999), Arcana (1996-2008) ou Photogenic Drafts (1991) - para citar apenas alguns lidam com imagens encontradas e fazem da apropriação artística uma estratégia operativa central (Fig.1). Não é, pois, surpreendente que estes trabalhos tenham motivado o debate em torno da questão da autoria, especialmente porque o autor se torna uma categoria ambígua quando falamos de obras que seleccionam e expõem imagens produzidas por outros. De Richard Prince a Sherrie Levine, o impacto da apropriação artística sobre as categorias autorais é bem conhecido mas, ainda assim, será produtivo reconsiderar aqui este conceito, uma vez que os museus continuam a ser instituições fortemente responsáveis pela criação e invenção de autores, em todas as suas tipologias. Apesar de, na sua prática artística, Joachim Schmid recorrer a diversas estratégias de apropriação, proponho antes que nos detenhamos especificamente num dos seus projectos que parece levar o problema da autoria um pouco mais longe.

Em 1989, os artistas Joachim Schmid e Adib Fricke desenvolveram em conjunto a obra Masterpieces of Photography. The Fricke and Schmid Collection. Tal como o título indica, este projecto consistia na apresentação pública de uma colecção privada que prometia revelar, por ocasião do $150 .^{\circ}$ aniversário da fotografia, uma ostensiva quantidade de fotografias inéditas, alegadamente assinadas por grandes protagonistas da história da fotografia (Fig. 2). Aparentemente, esta colecção permitiria que novas fotografias, até então desconhecidas, tiradas por August Sander, Ansel Adams ou Cindy Sherman, entre outros importantes fotógrafos, pudessem finalmente chegar a público, para fascínio e deleite geral. Apenas aparentemente, porém. 


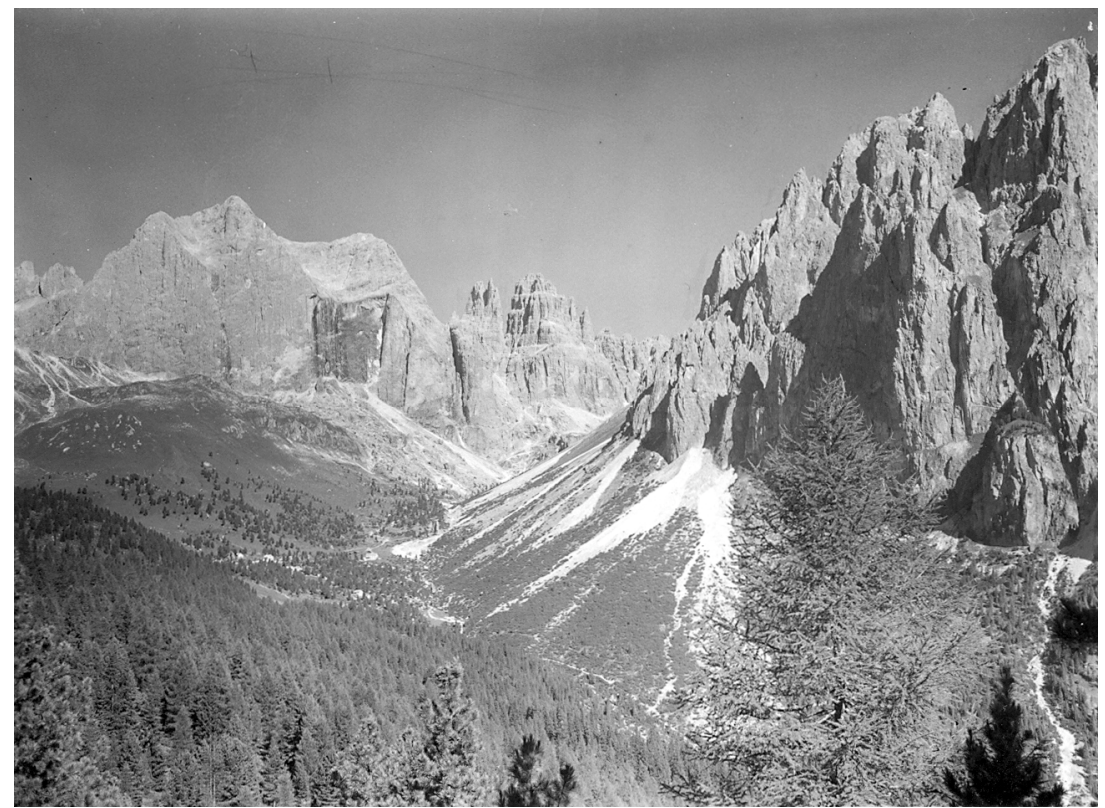

Fig.2.

Joachim Schmid, Masterpieces of Photography, The Fricke and Schmid Collection. Ansel Adams, 1989.

Fonte: $\underline{\text { http://schmid.wordpress.com/ }}$

Com efeito, as obras-primas expostas não tinham sido propriamente criadas pelos grandes nomes da fotografia, ao contrário do que se proclamava. Na verdade, as mesmas foram adquiridas em feiras e mercados de velharias, e não são mais do que imagens de fotógrafos anónimos e amadores. Contudo, todas estas fotografias apresentavam uma interessante particularidade: elas assemelhavam-se, de forma muito convincente, aos estilos de autores consagrados. Nesta medida, as fotografias apresentadas na Fricke and Schmid Collection não eram, afinal, obras-primas de artistas reputados, apesar de muito se parecerem com elas. Mas uma vez que estas imagens já eram tão semelhantes a obras de fotógrafos de renome, bastaria fornecer apenas mais alguns elementos de legitimação artística para que as mesmas pudessem funcionar como obras-primas, e serem vistas como tal. Deste modo, Fricke e Schmid criaram falsas atribuições fotográficas, inicialmente baseadas nas semelhanças de estilo e composição, facto que foi depois reforçado pela plausibilidade dos títulos e datas que igualmente inventaram. Neste projecto, os artistas adoptaram assim o papel do museu, encarnando, em particular, a autoridade institucional que normalmente garante ao público a certeza de que se encontra perante obras de arte autênticas e originais. Através da exposição destas fotografias, os espectadores continuavam a estar, afinal, perante obras de arte autênticas e originais - embora não no sentido inicialmente esperado.

Para além de tudo isto, Masterpieces of Photography aproxima-se ainda, perigosamente, do domínio da falsificação artística. Por um lado, e tal como os falsários 
também fazem, as fotografias da Fricke \& Schmid Collection demonstram bem como as características alegadamente únicas que identificam o estilo distintivo de um artista proeminente podem, em última análise, não ser assim tão únicas. Por outro lado, elas revelam igualmente a fragilidade do valor da autoria das obras de arte, relevando ainda como este valor pode não assentar necessariamente em autores reais, dependendo antes de outros factores exteriores. Tal como se pode ler num artigo recentemente publicado acerca do escândalo de falsificação que envolveu a negociante de arte Glafira Rosales: “... apesar de os falsificadores de arte causarem algum dano a nível económico, eles também proporcionam entretenimento público, expondo os verdadeiros valores que regem afinal o mercado de arte" (IN PRAISE, 2013). No caso das alegadas obras-primas fotográficas apresentadas por Fricke e Schmid, não se infligiu dano algum sobre os mercados, uma vez que a encenação cedo se desvaneceu. Mas a partir deste projecto, a confiança nas afirmações artísticas de Joachim Schmid nunca mais foi a mesma.

\section{O MUSEU, A HISTÓRIA E A FOTOGRAFIA COMO ARTEFACTO}

Ao longo dos últimos anos e de forma constante, Joachim Schimd tem vindo a internalizar funções de museu nos seus gestos artísticos, e o facto de o próprio Schmid ser um ávido coleccionador terá, certamente, contribuído para tal. Porém, Schmid é um coleccionador peculiar, uma vez que colecciona preferencialmente materiais fotográficos pré-existentes, geralmente vernaculares e anónimos, praticamente sem valor de mercado. Apesar da natureza discreta destes materiais, o artista colecciona-os de forma compulsiva, o que o conduziu inevitavelmente a um previsível problema: como lidar então com o grande número de imagens recolhidas e como as organizar? Esta questão constitui o cerne de um dos seus mais longos e impressionantes projectos, Archiv (1986-1999), um trabalho no qual o artista interroga o efeito-museu, através do recurso à lógica classificatória do arquivo (Fig. 3).

Em 1999, quando Joachim Schmid decidiu por termo a este projecto desenvolvido ao longo de treze anos, Archiv era constituído por 725 painéis, nos quais o artista havia organizado as imagens recolhidas de acordo com uma série de novas categorias e géneros. $\mathrm{O}$ vasto corpus de milhares fotografias comuns, comerciais e domésticas foi seriado por Schmid segundo tipologias específicas definidas pelo próprio - pessoas com cães, o carro novo, casamentos, postais com imagens de motéis, celebridades desportivas, etc. 

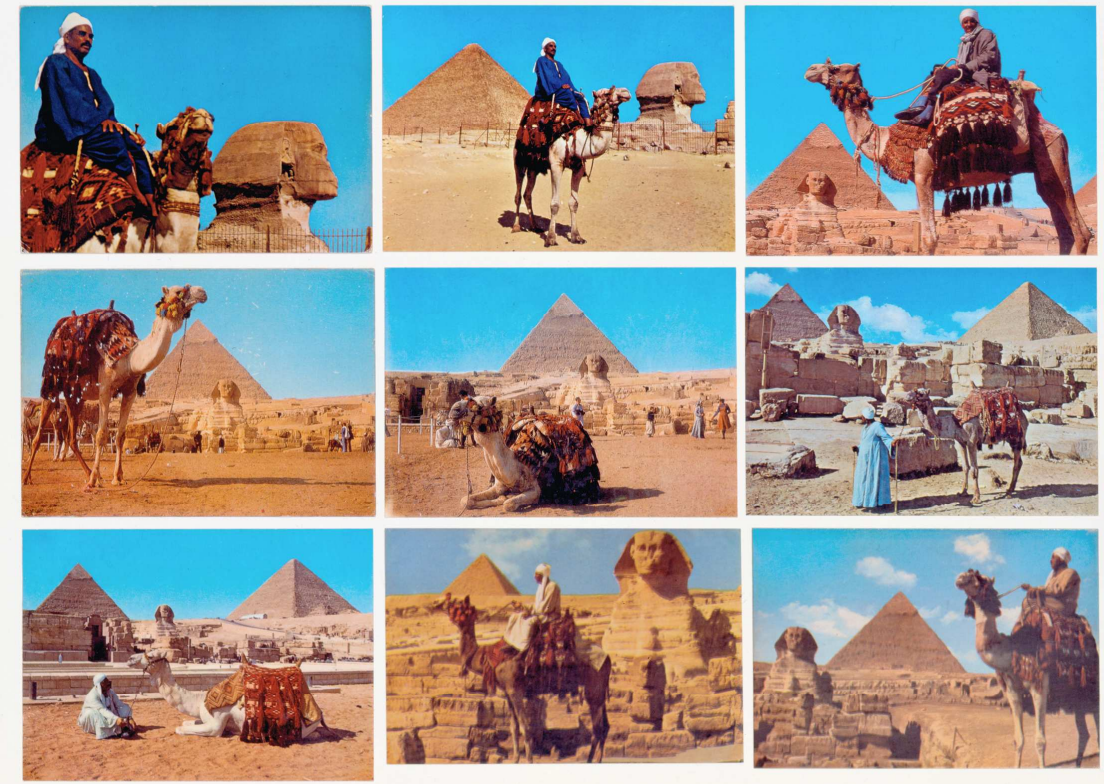

Fig.3.

Joachim Schmid, Archiv, 1986-1989. No. 85, 1989

Fonte: http://schmid.wordpress.com/

Através desta classificação arquivística, Schmid propôs-se gerar o que ele designou por "um panorama da fotografia do século XX" (SCHMID, 2014), dado que muitas das categorias criadas são facilmente reconhecíveis e traçam um mapeamento dos usos mais comuns de grande parte das imagens fotográficas produzidas. Em simultâneo, Archiv dialoga também com o museu de arte na medida em que, neste projecto, o valor estético comummente valorizado pelos museus de arte é, aqui, ostensivamente refutado. Este projecto fotográfico, diz-nos o autor, é um grande panorama "com alguns campos em falta, tais como a fotografia artística, a fotografia de moda ou a fotografia jornalística - ou seja, os campos com que os outros geralmente se importam"(ver WEBER, 2007, p.71). Assim, ao deixar estas amplas categorias propositadamente fora do seu arquivo, o mesmo opta por se concentrar precisamente nas imagens que os museus e historiadores tantas vezes negligenciaram.

Curiosamente, a crítica de Schmid no que toca à apreciação artística da fotografia materializa-se em técnicas de exibição que não são típicas das exposições de arte, mas são antes mais comuns aos museus de história natural. Esta aproximação metafórica foi sugerida pelo próprio artista, alegando que cada painel representava uma "espécie" diferente de fotografia (WEBER, 2007, p.71). E uma vez que estas espécies de fotografia ainda não se encontravam claramente definidas - ao contrário daquelas a que Schmid procurou 
veementemente escapar -, o projecto criava assim a oportunidade perfeita para identificar os "tipos" de fotografia que Schmid considerava mais representativos das práticas fotográficas correntes. Desta organização sistemática emerge, no entanto, o olhar clínico, distante e controlador do arquivo e do museu, que também evidencia a autoridade histórica que subjaz a essa maneira disciplinar de olhar. ${ }^{2} \mathrm{O}$ mais impressionante deste recurso expositivo, porém, é que através dele Schmid acaba também por enfatizar quão eficientes e poderosos podem ser os fenómenos retóricos de exibição.

Para além da reflexão sobre o que os museus decidem integrar ou excluir, o trabalho de Joachim Schmid interessa-se por explorar as políticas do olhar que são criadas e mantidas pelas instituições museológicas. Em 2000, Joachim Schmid foi convidado pela historiadora de fotografia Elizabeth Edwards, à data curadora do Museu Pitt Rivers, em Oxford, para desenvolver uma intervenção site-specific nas áreas públicas do museu (nesse período, o Pitt Rivers desafiava frequentemente artistas contemporâneos a trabalhar, comentar e responder ao espaço do museu e às suas colecções antropológicas e etnográficas). Uma vez que Schmid já tinha trabalhado previamente com "imagens recicladas", mas também com a ideia de colecções e histórias imaginadas, Edwards referiu que ele configurava "a escolha ideal para elaborar um trabalho que se destina a reavaliar pressupostos sobre materiais, valores e mudanças de significado" (EDWARDS, 2000, p.72).

Schmid respondeu ao convite de Edwards entusiasticamente, considerando que as potencialidades oferecidas pelo Pitt Rivers eram bastante mais "excitantes" e "eficientes" do que as dos museus de arte (EDWARDS, 2000, p.72). A sua intervenção nas galerias expositivas consistiu, concretamente, na inserção de postais do século $\mathrm{XX}$ nas vitrines clássicas do museu, lado a lado com os outros objectos da exposição permanente (Fig.4). Ao colocar estes postais em estreita coabitação com os restantes artefactos históricos, Schmid não estava apenas a atribuir-lhes uma relevância cultural semelhante; o artista estaria igualmente a questionar o que é que, nestes postais, tem valor cultural: as imagens que eles representam ou os postais propriamente ditos, enquanto objecto materiais?

\footnotetext{
${ }^{2}$ Para mais sobre enquadramentos disciplinares, veja-se (BENNET, 1988).
} 


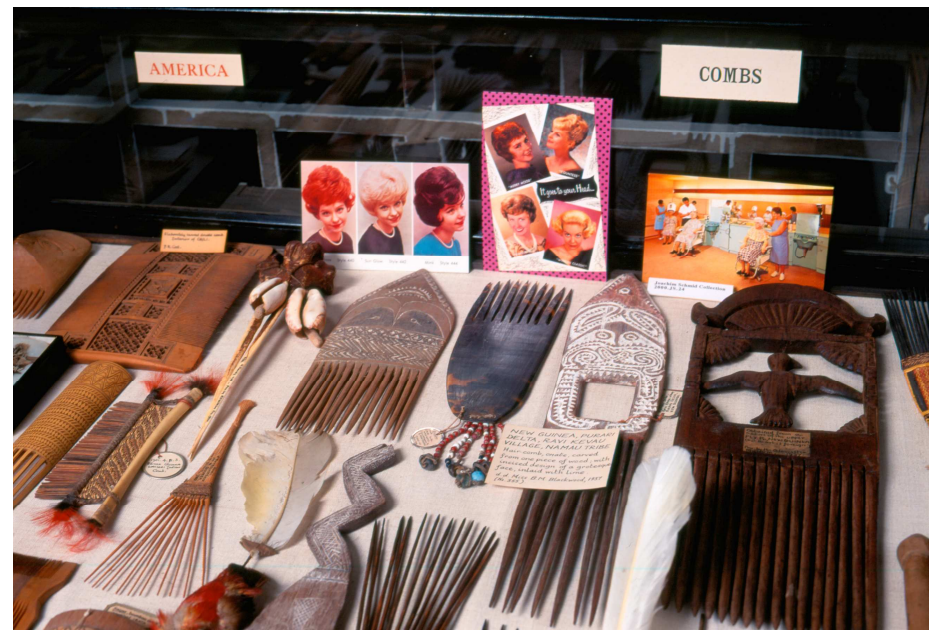

Fig.4.

Joachim Schmid, The Joachim Schmid Collection at the Pitt Rivers Museum, 2000-2002

Fonte: http://schmid.wordpress.com/

O poderoso diálogo que os postais de Schmid estabeleceram com o ambiente histórico do museu, origina em simultâneo dissonância e consonância. Por um lado, a presença dos postais contém um elemento surpreendente e disruptivo; no entanto, por outro, cada um destes postais foi ironicamente integrado em plena concordância com a taxonomia de cada vitrine. Desta forma, postais de salões de cabeleireiros e de penteados surgem na vitrine "Pentes nativo-americanos", enquanto que a imagem de uma enfermeira junto a líquidos farmacêuticos figura na secção "Instrumentos Cirúrgicos Primitivos". Na mesma esteira humorística, um postal de Marilyn Monroe usando jóias pontua a vitrine denominada "Contas de Pedra, Vidro e Cerâmica", enquanto que imagens de gôndolas venezianas se encontram entre pequenos modelos de barcos e canoas. Ao todo, 22 postais acabaram por formar a Joachim Schmid Collection at the Pitt Rivers Museum, seguindo a grande tradição museológica de designar as suas colecções de acordo com o nome dos coleccionadores originais. Curiosamente, a designação do projecto revelou-se particularmente acertada, uma vez que a Joachim Schmid Collection acabou por ser efectiva e formalmente integrada nas colecções do Pitt Rivers, após a exposição temporária ter terminado.

O que neste projecto se evidencia, é o facto de a cultura ocidental moderna poder ser categorizada e apresentada através dos mesmos recursos que geralmente são activados para a exposição do passado e do Outro - se ao menos as pessoas conseguissem olhar para a sua própria cultura como outsiders. Os postais parecem assim desafiar de forma auto-reflexiva o nosso entendimento do que é o exótico e, ao mesmo tempo, eles também contaminam as dinâmicas do olhar etnográfico, alterando profundamente a percepção dos visitantes face a 
este tipo de museus. A instalação de postais de Schmid desencadeia pois uma absoluta subversão, uma vez que expõe claramente os mecanismos do olhar e de sistematização que se encontram em jogo no museu, materializando e dando substância ao que parece natural nestes espaços de exposição mas que é suposto passar despercebido. O discreto papel da instituição, e a natureza do efeito-тиseu, tornam-se assim intensamente visíveis. Para além disso, a crítica ao museu que Schmid elabora neste projecto torna-se ainda mais sofisticada porquanto a mesma não é feita através de uma mera rejeição do contexto institucional. Pelo contrário, ela funciona dentro, e através do espaço museológico, em forte diálogo com as suas colecções, dando corpo a uma refinada obra conceptual que sai reforçada pelo facto de se definir no interior da mesma instituição que o artista pretende comentar.

A atenção que Schmid tem dirigido ao funcionamento e às implicações das instituições museológicas não emergiu apenas como consequência destas encomendas de museus. O seu interesse nos temas do museu atravessaram já outros projectos anteriores e um deles, em especial, mostra-se particularmente pertinente nesta análise, uma vez que pressupõe uma negociação com uma outra função museológica importante: a da preservação.

\section{POLUIÇÃO FOTOGRÁFICA: RECICLAR AS IMAGENS DO PLANETA}

Muito antes da intervenção dos postais no Museu Pitt Rivers, Joachim Schmid publicou, em 1990, um anúncio no jornal. Este anúncio procurava mobilizar as pessoas que tivessem fotografias antigas em seu poder, e que desejassem desfazer-se delas, a seguir um método adequado para o efeito. Tal procedimento consistia em remeter essas fotografias para o Instituto para o Reprocessamento de Fotografias Usadas - uma instituição alegadamente oficial, igualmente responsável pela recolha e administração da Primeira Colecção Geral de Fotografias Usadas. O gesto artístico patente neste apelo apresentava razões puramente ecológicas: o texto alegava que existiam já demasiadas fotografias no mundo e que, por esta razão, as pessoas deveriam estar conscientes de que a produção descontrolada de imagens estaria a criar graves problemas ao meio ambiente, não só pela perigosa composição química das próprias fotografias, mas também pelas prementes questões de poluição visual. Evocando os temas do excesso e do desperdício, o pequeno anúncio incitava assim as pessoas encontrar formas profissionais de lidar com fotografias velhas ou, alternativamente, de as reciclar.

Como consequência de tal exortação pública, o ficcional Instituto para o Reprocessamento de Fotografias Usadas recebeu efectivamente milhares de fotografias, que 
depois seriam reprocessadas artisticamente. Através desta instituição, Joachim Schmid superava o papel do artista enquanto curador; neste projecto, o artista agia também como repositório museológico, assumindo a responsabilidade de cuidar das imagens recebidas, conferindo-lhes uma nova vida, necessariamente diferente. Encontramos portanto no trabalho de Schmid a noção do artista enquanto museu, se considerarmos os museus como instituições que combinam exemplarmente, as funções de exibição, armazenamento e preservação de objectos culturalmente relevantes. Se um dos traços distintivos dos museus é precisamente o facto de terem objectos à sua guarda, o instituto de Schmid assume igualmente essa vocação museológica, na medida em que propõe fornecer as condições necessárias para que estes objectos possam sobreviver através dos anos e fiquem, deste modo, acessíveis às gerações futuras.

Na peculiar relação amor-ódio que Schmid trava com o museu, importa destacar o papel da categoria da excepcionalidade. Se esta é uma noção fulcral para os museus - tanto ao nível da materialidade como de um ponto de vista estético - ela é igualmente a categoria que o artista mais tem afrontado e desafiado no tipo de imagens fotográficas com que trabalha. De um modo geral, a maior parte das fotografias amadoras e populares que Schmid recuperou e reciclou ao longo dos anos pode ser entendida como desinteressante, repetitiva e pouco original - embora não necessariamente irrelevante. Geoffrey Batchen, na sua reflexão sobre o instantâneo fotográfico - o snapshot - salienta que uma das características mais proeminentes deste género fotográfico, ubíquo e abundante, é efectivamente o facto de ele ser constituído por "fotografias desinteressantes" e banais (BATCHEN, 2008, p.121-123). Os aspectos incaracterísticos e triviais que caracterizam essas aborrecidas fotos instantâneas, tanto na forma como no conteúdo, nada têm que ver, contudo, com o poderoso papel afectivo que elas ocupam nas narrativas pessoais e familiares que originalmente as enquadram. Segundo Batchen, foi também esta ausência de características marcantes que determinou a longa invisibilidade e inexistência de estudos sobre este tipo de imagens, no âmbito disciplinar da história da arte. Em particular, argumenta Batchen, os snapshots fotográficos eram imagens extremamente desconcertantes para a história da arte, uma vez que, até há bem pouco tempo, esta disciplina não possuía os recursos metodológicos que lhe permitissem lidar com imagens comuns, vulgares, e não-excepcionais.

A prática coleccionista de imagens em segunda mão que Joachim Schmid tem desenvolvido na sua obra, sugere uma preocupação similar face ao valor que os circuitos da arte têm atribuído a estas discretas fotografias comuns. Mais concretamente, as suas colecções 
de "espécies visuais" vulgares evidenciam o compromisso de Schmid em explorar, e especialmente em inverter, as diferentes posturas e formas de actuar dos museus. Várias das suas séries como Bilder von der Straße (1982-2012) [Fotografias da Rua], Belo Horizonte (1992, 1993, 2002) ou Arcana (1996/2008), são atravessadas por uma forte componente de crítica institucional. Nestes trabalhos, Schmid recolheu das ruas milhares de fotografias e negativos que tinham sido deliberadamente deitados fora no espaço público para assim entrarem num processo natural de esquecimento e de destruição. Ao recuperar e recolher estas imagens descartadas, Schmid dedicou uma parte importante do seu trabalho a resgatar e a investigar os sentidos sociais, poéticos e afectivos destes abundantes vestígios da cultura visual popular.

O interesse concreto nos temas do desperdício e do excesso que se encontra ao longo destes projectos ganha especial relevância se os observarmos através da lente do museu que aqui tem sido referida. Após as preocupações ambientais do Instituto para o Reprocessamento de Fotografias Usadas, Joachim Schmid deu início a outro ambicioso projecto intitulado Photographic Garbage Survey Project (1996/97). Esta pesquisa consistia em recolher e preservar imagens abandonadas encontradas na rua e, mais uma vez, Schmid imita o museu, revisitando desta vez a sua burocracia. Criou um formulário oficial, preenchido com informação factual, forjando assim institucionalmente o valor e a validade de uma colecção composta sobretudo por despojos de imagens populares. Joachim Schmid recupera novamente a gramática da ecologia ao alegar que, no seu projecto, todos os formulários têm a capacidade de "formar um compêndio internacional da poluição fotográfica nas cidades modernas" (SCHMID 2014, tradução nossa). Embora o termo "poluição" possa ser uma referência metafórica para o consumo excessivo de imagens na cultura popular, tal poluição constitui também um tipo de lixo que o artista considera ser extremamente precioso:

"De facto, considero que as quase 400 fotografias que encontrei são um tesouro. Algumas delas são imagens extremamente fascinantes (a humanidade tê-las-ia perdido irremediavelmente se eu não tivesse intervindo) e o conjunto total forma um compêndio único de lixo fotográfico, um anti-museu. Embora os museus coleccionem e preservem as fotografias que, de acordo com o consenso geral da nossa sociedade, são amostras importantes da nossa cultura e que devem ser mantidas para o futuro, eu estou a especializar-me naquelas imagens que são claramente consideradas tão inadequadas e irritantes que os seus criadores e donos pensaram que as mesmas não deviam ter qualquer futuro. Estas imagens representam a outra metade da nossa cultura" (SCHMID 2014). 
Tal como a declaração atesta, é ao olhar para o outro lado do espelho (para a outra metade da nossa cultura), que Joachim Schmid reabilita a relevância artística das imagens descartadas, criando assim o seu próprio Salon des Refusés da fotografia moderna. Por esta razão, é importante salientar que, embora Schmid afirme que estas fotografias indesejadas configuram um "anti-museu", esta designação deve ser lida cuidadosamente, uma vez que Schmid recorre, ainda assim, a operações profundamente museológicas na sua forma de fazer arte. Todo o desafio das hierarquias e das funções culturais do museu é conseguido ironicamente, através de intervenções artísticas fortemente imbuídas, também elas, de vocação museológica e institucional.

\section{NO LIMITE: PARA UM MUSEU IMATERIAL DA FOTOGRAFIA}

Embora várias das obras acima descritas procurem confrontar e superar os poderes legitimadores do museu, a verdade é que este continua a estar marcadamente presente nas relações entre artistas e instituições. Uma tentativa porventura mais eficaz de ultrapassar derradeiramente o museu poderá talvez ser encontrada num dos últimos trabalhos de Schmid, intitulado Other People's Photographs (2008-2011). Neste projecto, Schmid não reformulou apenas o seu posicionamento relativamente ao museu, mas enveredou também por outra via, explorando o impacto das recentes transformações tecnológicas, nomeadamente do digital, na materialidade da fotografia. Apesar de regressar aqui à estratégia de apropriação, que sempre lhe foi cara, Schmid fá-lo desta vez em moldes bastante diferentes. O recurso a fotografias de outras pessoas não era exactamente uma novidade para Schmid; contudo, esta foi provavelmente a primeira vez em que, no seu trabalho, o gesto de apropriação não era apenas pós-moderno mas afirmava-se sobretudo como pós-fotográfico. A noção de pós-fotografia, tal como foi definida por Geoffrey Batchen, tem em si um duplo sentido peculiar. Não só diz respeito a algo que emerge da aparente ameaça que o digital veio provocar na vida das fotografias tradicionais; refere-se também a um momento histórico específico em que nos encontramos já "após" a fotografia, mas não ainda "para além da fotografia" (BATCHEN, 1994, p.47; 2000, p.109-110).

Numa descrição rápida, Other People's Photographs é uma colecção de livros fotográficos, em 96 volumes, na qual Schmid reuniu o resultado de um vasto trabalho de pesquisa realizado em torno de imagens fotográficas amadoras. Desta vez, porém, a pesquisa não foi realizada na rua como habitualmente (dado que as pessoas cada vez imprimem menos 
fotografias, é cada vez mais difícil encontrar fotografias nas ruas), mas sim no local onde hoje em dia reside o maior número de fotografias: na internet. A partir da investigação efectuada em plataformas de partilha de imagens online, nomeadamente no Flickr, Joachim Schmid propõe delinear "uma biblioteca de fotografia amadora contemporânea, na era do digital e da partilha online de fotografias" (SCHMID, 2014). À medida que a sua pesquisa na internet evidenciava a recorrência de certos padrões e tipologias, Schmid decidiu organizar o resultado da sua pesquisa numa colecção abrangente de livros, em que cada livro corresponde a um particular conceito ou entrada, se quisermos manter a terminologia enciclopédica. Assim, um dos volumes da colecção inclui, por exemplo, apenas imagens do pôr-do-sol (Sunset), enquanto outros contêm apenas fotografias de pessoas a fotografar a sua própria sombra (Shadow) ou de reflexos (Objects in Mirror). Noutros casos, encontramos livros exclusivamente constituídos por fotografias de diferentes tipos de objectos (Collections), ou por coisas que se podem encontrar em sacos ou malas (Contents) ou mesmo por refeições servidas a bordo de viagens de avião (Airline Meals) - numa variedade de temas que atesta bem o alcance e a heterodoxia do projecto artístico de Schmid (Fig.5).
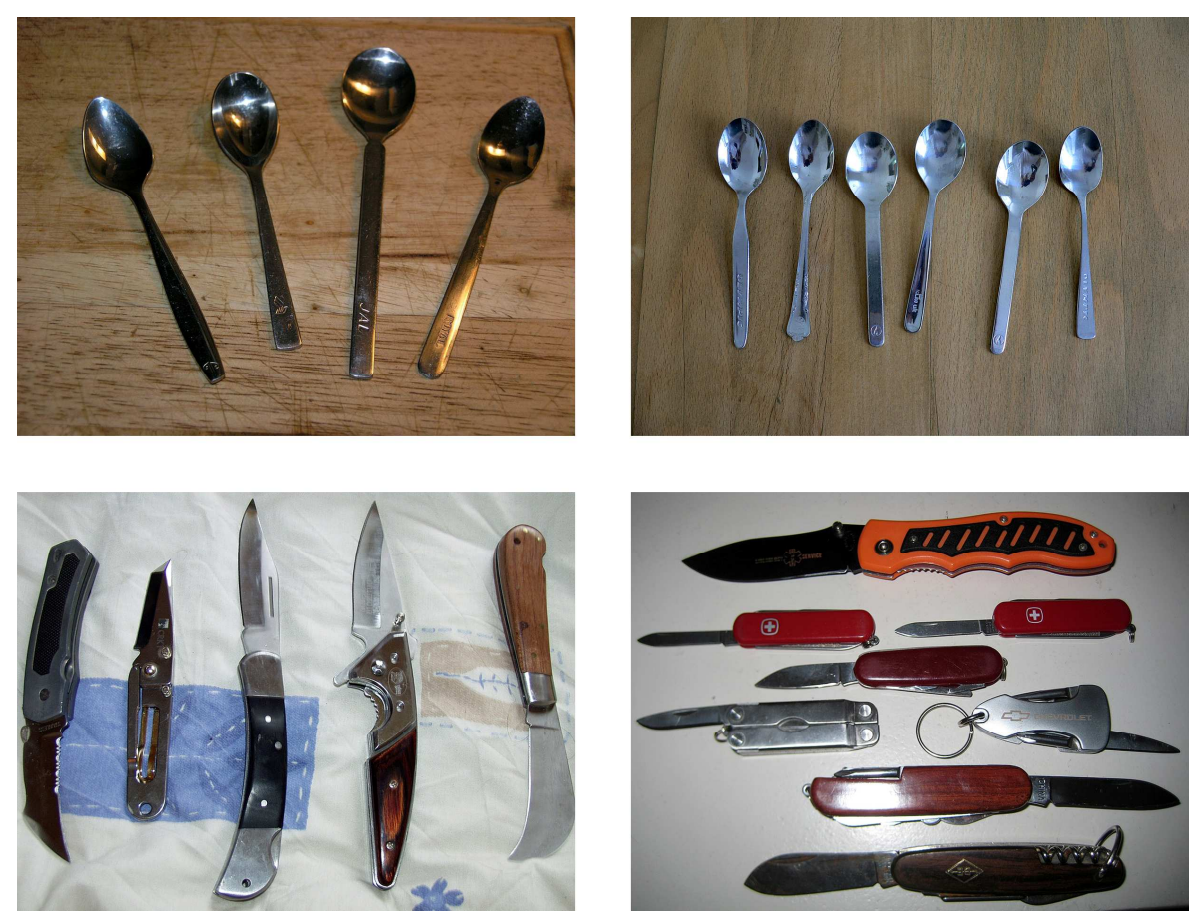

Fig.5.

Joachim Schmid, Other People's Photographs, 2008-2011. Collections.

Fonte: http://schmid.wordpress.com/ 
Esta classificação sistemática dos temas emergentes da fotografia popular tem aqui uma dupla qualidade. Por um lado, Schmid está seriamente empenhado em consolidar a presença destas novas categorias visuais nas esferas culturais, e talvez tenha sido essa a razão que o fez optar pelo livro (álbum) - um formato historicamente ligado à estabilização e divulgação do conhecimento - para servir os seus propósitos. No entanto e, por outro lado, os conceitos invulgares que dão nome a cada um destes volumes acrescentam alguma incongruência às categorias tradicionais do conhecimento. Como tal, apesar dos mecanismos institucionais que podem ainda ser identificados neste projecto editorial, Other People's Photographs concretiza uma crítica elaborada no que toca às próprias noções de taxonomia e classificação, normalmente adscritas aos domínios do museu, da biblioteca ou do arquivo. Com esta crítica, Joachim Schmid acaba por lançar uma interrogação ainda mais profunda sobre a obsolescência de certas instituições e práticas artísticas, sendo que o faz sobretudo sem qualquer tipo de nostalgia.

O enorme decréscimo de fotografias impressas que caracteriza a presente era digital teve um sério impacto no modo como lidamos com as imagens fotográficas, parecendo mesmo justificar certo revivalismo estético, presente por exemplo nos filtros "antigos" que se encontram disponíveis na edição fotográfica digital, ou na revitalização dos processos históricos da fotografia analógica. As mudanças geradas pela nova condição imaterial da fotografia tiveram também severas consequências para Joachim Schmid, uma vez que a materialidade costumava ser uma condição necessária à prática da apropriação artística. No entanto, o trabalho de Schmid não revela um artista particularmente atormentado pelo desaparecimento das tradicionais fotografias físicas.

Pelo contrário, obras recentes como Other People's Photographs demonstram claramente que o artista foi capaz de aceitar e de incorporar de forma muito positiva, as profundas transformações desencadeadas pelo paradigma tecnológico actual. Este posicionamento optimista transparece não só nos processos de pesquisa de Schmid, que agora acontecem online, mas muito especialmente na solução encontrada pelo artista para a produção dos diferentes volumes. Ao rejeitar a ideia de preciosismo normalmente associada aos livros de artistas (muitas vezes edições limitadas ou obras manufacturadas únicas), os 96 volumes desta série chegam ao ponto de nem sequer parecerem precisar da intervenção directa do artista. Estes livros de arte podem, na verdade, ser comprados online, a preços surpreendentemente baixos, unicamente através de empresas print-on-demand que são responsáveis por imprimir e enviar os volumes desejados directamente ao comprador. 
As obras artísticas são então livros online, feitos de fotografias online, que só se convertem em objectos materiais se o público os encomendar, também online. Com esta solução inventiva, Schmid faz mais do que revisitar algumas das questões museológicas que foram aqui discutidas; o artista consegue ultrapassar em pleno as funções de intermediação geralmente reconhecidas aos museus e aos espaços de exposição. Para além disso, a intervenção conceptual que Schmid concretiza apenas ao nível do virtual e da pré-produção, desafia também as regras estabelecidas no mercado de arte: estes volumes não se limitam a ser obras de arte baratas e acessíveis; elas podem também ser adquiridas sem que tenham de passar pelos agentes tradicionais da mediação artística. Assim, Schmid estabelece uma relação directa e democrática com o seu público enquanto o seu trabalho consegue simultaneamente contornar as clássicas etapas institucionais de aprovação e validação.

Para concluir, importa sublinhar o modo como Joachim Schmid foi capaz de adaptar e redireccionar a sua prática artística às revoluções geradas pelo paradigma digital da fotografia. Se, nos dias de hoje, quantidade e abundância são, provavelmente, os aspectos mais impressionantes da fotografia, as últimas obras de Schmid já não demonstram a preocupação ecológica dos anos 90 no que toca ao excesso de imagens no mundo. Pelo contrário, Schmid reconhece o emocionante potencial da actual abastança visual, e as suas obras parecem implicitamente pedir às pessoas que não parem de fazer novas fotografias. Ao abraçar com entusiasmo as novas possibilidades tecnológicas da fotografia amadora, Joachim Schmid não se encontra apenas interessado nos espaços virtuais na medida em que estes lhe permitem encontrar a matéria-prima para os seus projectos. Em Other People's Photographs, Schmid mostra-se particularmente sensível à emergência e ao funcionamento das novas instituições não-artísticas e não-museológicas, que o artista volta a questionar, confrontando-as e explorando-as, novamente a partir do seu interior.

\section{AGRADECIMENTOS}

A autora agradece o apoio da Fundação para a Ciência e a Tecnologia através dos projectos SFRH/BPD/79102/2011 e PTDC/CPC- HAT/4533/2014. 


\section{REFERÊNCIAS}

IN PRAISE of Art Forgery. The Emperor's New Pictures. Fakes Say Some Interesting Things About the Economics of Art. The Economist, n.21, Setembro 2013. Disponível em: $<$ http://www.economist.com/news/leaders/21586580-fakes-say-some-interesting-thingsabout-economics-art-emperors-new-pictures>. Acesso em: set. 2014.

ADORNO, Theodor W.. Valéry Proust Museum. Prisms. Cambridge (MA): The MIT Press, 1967.

ALTSHULER, Bruce. Collecting the New: Museums and Contemporary Art. Princeton NJ, Oxford: Princeton University Press, 2007.

BATCHEN, Geoffrey. Phantasm. Digital Imaging and the Death of Photography. Aperture. Nova Iorque, n. 136, p. 47-51, jun. 1994.

BATCHEN, Geoffrey. Each Wild Idea. Writing, photography, history. Cambridge (MA), London: The MIT Press, 2000.

BATCHEN, Geoffrey. Snapshots. Art history and the ethnographic turn. Photographies. Londres, v. 1, n. 2, p. 121-142, set. 2008

BENNETT, Tony. The Exhibitionary Complex. New Formations. Vol.4, p.73-102, 1988.

CRIMP, Douglas. On the Museum's Ruins. October, Nova Iorque, n.13, p.41-57, Summer 1980.

CRIMP, Douglas. The Photographic Activity of Postmodernism. October, Nova Iorque, n. 15, p.91-101, Winter 1980a.

Elizabeth EDWARDS, The Joachim Schmid Collection at the Pitt Rivers Museum. In: COOTE, Jeremy; MORTON, Chris; NICHOLSON, Julia (Org.). Transformations: The Art of Recycling. Oxford: Pitt Rivers Museum, University of Oxford, 2000.

FRASER, Andrea. From the Critique of Institutions to an Institution of Critique. Artforum, v.44, n.1,

MALRAUX, André. Museum without Walls. Londres: Secker and Warburg, 1965.

McSHINE, Kynaston (Org.). The Museum as Muse: Artists Reflect. Nova Iorque: Museum of Modern Art, 1999.

SCHMID, Joachim. Archiv (1986-1999). Disponível em:

<https://schmid.wordpress.com/works/1986-1999-archiv/>. Acesso em: 1 ago. 2014.

SCHMID, Joachim. Works, Photographic Garbage Survey Project (1996-1997). Disponível em: <https://schmid.wordpress.com/works/1996-1997-photographic-garbagesurvey-project/>. Acesso em: 1 ago. 2014. 
SCHMID, Joachim. Works, Other People's Photographs (2008-2011). Disponível em: $<$ https://schmid.wordpress.com/works/2008\%E2\% 80\%932011-other-people\%E2\%80\%99sphotographs/>. Acesso em: 1 ago. 2014.

WARD, Frazer. The Haunted Museum: Institutional Critique and Publicity. October, Nova Iorque, n. 73, p. 278-286, 2005.

WEBER, John S.. Archiv. In: MACDONALD, Gordon; WEBER, John S. (Org.). Joachim Schmid. Photoworks 1982-2007. Brighton, New York, Gottingen: Photoworks, Tang, Steidl, 2007. 